\title{
Nanoscale Chemical Imaging of the Reduction Behavior of a Single Catalyst Particle**
}

\author{
Emiel de Smit, Ingmar Swart, J. Fredrik Creemer, Chithra Karunakaran, Drew Bertwistle, \\ Henny W. Zandbergen, Frank M. F. de Groot, * and Bert M. Weckhuysen*
}

When studying catalyst materials by in situ chemical microspectroscopy, a trade-off is found between the spatial resolution and chemical information of the acquired images. Microscopes utilizing ultraviolet, visible, or infrared radiation often obtain valuable chemical information from the sample, even under reaction conditions. ${ }^{[1-3]}$ However, the spatial resolution of these methods is, in principle, diffraction limited to, in the best cases, several hundreds of nanometers. Conversely, scanning probe techniques ${ }^{[4,5]}$ and electron microscopy $(\mathrm{EM})^{[6,7]}$ offer sub-nanometer resolution. Unfortunately, chemical information is difficult to obtain from these methods, especially under realistic reaction conditions. Scanning transmission X-ray microscopy (STXM) $)^{[8]}$ is a novel microspectroscopic technique that has, until now, rarely been used to characterize catalyst materials. STXM combines a high spatial resolution, roughly $15 \mathrm{~nm}$, with high chemical speciation potential by X-ray Absorption Spectroscopy (XAS), using focused soft X-ray light $(200-2000 \mathrm{eV})$ as a probe. The use of the method for characterization of catalyst

[*] E. de Smit, Dr. I. Swart, Dr. F. M. F. de Groot,

Prof. Dr. B. M. Weckhuysen

Inorganic Chemistry and Catalysis

Debye Institute for Nanomaterials Science, Utrecht University

Sorbonnelaan 16, 3584 CA Utrecht (The Netherlands)

Fax: (+31) 30-251-1027

E-mail:f.m.f.degroot@uu.nl

b.m.weckhuysen@uu.nl

Dr. J. F. Creemer

DIMES-ECTM, Delft University of Technology

P.O. Box 5053, 2600 GB Delft (The Netherlands)

Prof. Dr. H. W. Zandbergen

Kavli Institute of NanoScience, National Centre for High Resolution Electron Microscopy, Delft University of Technology

P.O. Box 5053, 2600 GB Delft (The Netherlands)

Dr. C. Karunakaran, D. Bertwistle

Canadian Light Source, Inc., University of Saskatchewan

Saskatoon, SK, S7N 0X4 (Canada)

[*** Financial support is acknowledged from the Dutch National Science Foundation (CW-NWO/VICI program) (F.M.F.d.G. and B.M.W.), The Netherlands Research School Combination on Catalysis (NRSCC) (B.M.W.), Shell Global Solutions (B.M.W.) and NIMIC (H.W.Z). The nanoreactors were fabricated at the DIMES ICP-group and the Nanofacility of TU Delft. G. H. Hoveling and P. J. Kooyman of TU Delft are acknowledged for technical support and discussions, respectively. The research was performed at the Canadian Light Source (CLS), which is supported by NSERC, NRC, CIHR, and the University of Saskatchewan. The CLS-SM beamline and STXM were developed by K. Kaznatcheev (CLSI) with the assistance of A. P. Hitchcock.

D) Supporting information for this article is available on the WWW under http://dx.doi.org/10.1002/anie.200806003. materials under realistic conditions was envisioned by Drake et al. ${ }^{[9]}$ and recently fully exploited by our group. ${ }^{[10]}$ Our STXM nanoreactor system, originally designed for in situ TEM studies, ${ }^{[7]}$ allows treatment of catalytic solids at 1 bar and up to $500^{\circ} \mathrm{C}$, while imaging the morphology and the chemical identity of the active phases during reaction. Herein, we report on the reduction behavior of Fe-based FischerTropsch Synthesis (FTS) catalyst by imaging an individual catalyst particle at a resolution of $35 \mathrm{~nm}$ using STXM. A separate reduction experiment on the bulk catalyst was carried out to compare reduction phenomena at the nano (local) and macro (global) scale. The extent and rate of reduction of the iron oxide phase on the nanoscale is shown to strongly depend on the extent of interaction with the underlying support oxide.

Iron-based FTS catalysts convert syngas $\left(\mathrm{CO}\right.$ and $\left.\mathrm{H}_{2}\right)$ into long-chain hydrocarbons by a surface polymerization reaction, ${ }^{[11,12]}$ enabling the production of virtually contaminant (e.g. sulfur)-free chemical feedstocks, such as olefins, and transportation fuels, such as diesel, from sources other than crude oil, such as natural gas, coal, or biomass. Catalyst precursors typically consist of supported or unsupported iron oxide $\left(\alpha-\mathrm{Fe}_{2} \mathrm{O}_{3}\right.$ or $\left.\mathrm{Fe}_{3} \mathrm{O}_{4}\right)$ and it has been shown that the reduction pretreatment of this oxidic phase to a carbidic or metallic $\left(\mathrm{Fe}^{0}\right)$ phase is crucial in determining the final FTS performance. $^{[13,14]}$

The FTS catalyst under study has a starting composition of $\alpha-\mathrm{Fe}_{2} \mathrm{O}_{3}, \mathrm{~K}_{2} \mathrm{O}, \mathrm{CuO}$, and $\mathrm{SiO}_{2}$, in relative molar ratios of $\mathrm{Fe} /$ $\mathrm{Cu} / \mathrm{K} / \mathrm{Si}=100: 7.5: 5.9: 15.6 . \quad \mathrm{K}_{2} \mathrm{O}$ is added to enhance the catalyst performance, whereas $\mathrm{CuO}$ is added to improve the reduction rate of the $\mathrm{Fe}$ oxide phase. $\mathrm{SiO}_{2}$ serves as a support material and enhances the dispersion of the iron oxide crystallites. A STXM image of the single catalyst particle under study, before reduction at room temperature, and the average (signal from the whole particle) iron $\mathrm{L}_{3}$ and $\mathrm{L}_{2}$ and oxygen $\mathrm{K}$ absorption edges, are shown in Figure 1.

The double peak pre-edge feature in the $\mathrm{O} \mathrm{K}$ edge at around $530 \mathrm{eV}^{[15]}$ and the position of the main $\mathrm{L}_{3}$ edge peak contribution at $709.3 \mathrm{eV}^{[16]}$ (Figure 1b) indicate that the starting Fe species are present as a pure $\mathrm{Fe}^{3+} \alpha-\mathrm{Fe}_{2} \mathrm{O}_{3}$ phase. This phase is dispersed over the $\mathrm{SiO}_{2}$ support, as indicated by the extra characteristic contribution in the $\mathrm{O} \mathrm{K}$ edge spectrum at around $537 \mathrm{eV}^{[17]}$ The $\mathrm{O} \mathrm{K}$ edge was fitted to contributions of $\alpha-\mathrm{Fe}_{2} \mathrm{O}_{3}$ and $\mathrm{SiO}_{2}$ reference spectra at every $35 \times 35 \mathrm{~nm}^{2}$ pixel (Figure $1 \mathrm{a}$; see the Supporting Information). In this way, a chemical component image was reconstructed in which $\alpha-\mathrm{Fe}_{2} \mathrm{O}_{3}$ is shown in red and $\mathrm{SiO}_{2}$ in cyan. The resolution of the measurements is not high enough to resolve individual $\alpha-\mathrm{Fe}_{2} \mathrm{O}_{3}$ crystallites. However, it is clear 
a)
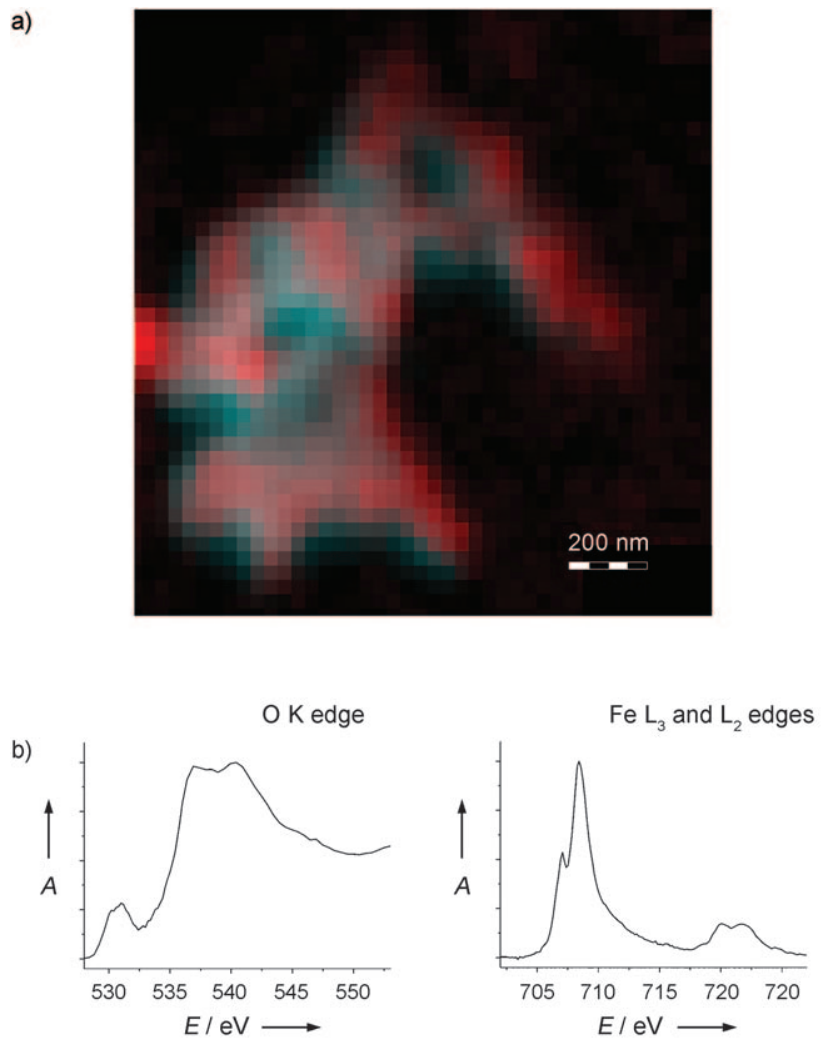

c)

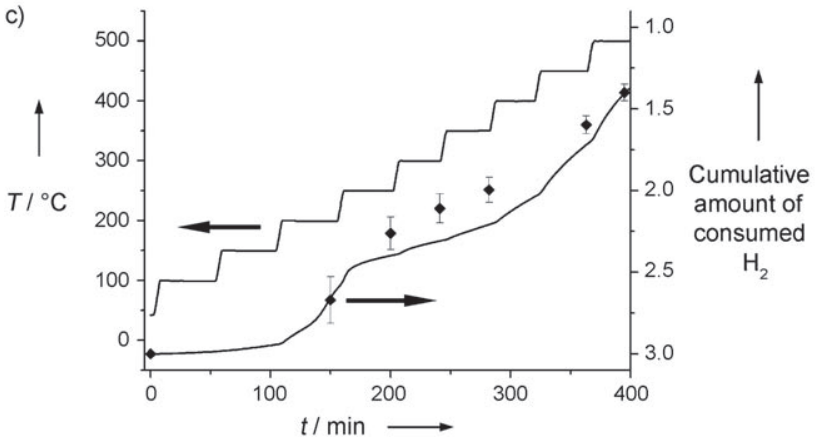

Figure 1. a) Chemical component image of the Fe-based FTS catalyst particle before reduction treatment. Red pixels indicate a contribution of the $\left(\mathrm{Fe}^{3+}\right) \alpha-\mathrm{Fe}_{2} \mathrm{O}_{3}$ phase, while cyan pixels indicate the presence of $\mathrm{SiO}_{2}$. The color intensity was normalized to the maximum signal of each species to emphasize the spatial distribution of the species. Pixel dimensions are $35 \times 35 \mathrm{~nm}^{2}$; b) average $\mathrm{O} K$ edge and $\mathrm{Fe} \mathrm{L}_{3}$ and $L_{2}$ edges of the catalyst particle before reduction; c) comparison of bulk TPR and STXM reduction data. The temperature program is plotted on the left y axis, the cumulative amount of consumed $\mathrm{H}_{2}$ on the right $y$ axis. Symbols $(\diamond)$ indicate the calculated average valence of the catalyst particle as determined by STXM and correspond to the values on the right $y$ axis. Error bars are indicated, assuming $5 \%$ error in the fitting procedure.

that the distribution over the $\mathrm{SiO}_{2}$ support is non-uniform (Figure $1 \mathrm{a}$ ). The presence of $\mathrm{Cu}$ and $\mathrm{K}$ in the catalyst was confirmed. However, these species were present in too low concentrations and too high dispersions to image them selectively. Therefore, we focused our study on the $\mathrm{Fe}$ and Si phases.
For reference, bulk reduction properties of the material were investigated using temperature programmed reduction (TPR; summarized in Figure 1 c). The catalyst was exposed to a flow of $\mathrm{H}_{2}$ while the temperature was increased, in steps of $50^{\circ} \mathrm{C}$, up to $500^{\circ} \mathrm{C}$ while monitoring the cumulative amount of consumed $\mathrm{H}_{2}$. Under the assumption of negligible $\mathrm{H}_{2}$ consumption by reduction of $\mathrm{Cu}$ species, this amount can be interpreted as a measure of the extent of reduction of $\mathrm{Fe}$ as a function of temperature.

To analyze the influence of local sample morphology on the STXM reduction data, an estimation of the $\mathrm{SiO}_{2}$ and $\alpha-$ $\mathrm{Fe}_{2} \mathrm{O}_{3}$ layer thicknesses was made (Figure $2 \mathrm{a}$ and the Supporting Information). Three regions of distinct chemical and morphological composition were defined. The first region (region 1) consisted of a thick layer of $\mathrm{SiO}_{2}$ (ca. $70 \mathrm{~nm}$ ) and a thick layer of $\alpha-\mathrm{Fe}_{2} \mathrm{O}_{3}$ (ca. $40 \mathrm{~nm}$ ), the second region (region 2) of a $\mathrm{SiO}_{2}$ layer of intermediate thickness (ca. $50 \mathrm{~nm}$ ) and a thin layer of $\alpha-\mathrm{Fe}_{2} \mathrm{O}_{3}$ (ca. $20 \mathrm{~nm}$ ), and finally, a region (region 3 ) with practically no $\mathrm{SiO}_{2}$ and a thin layer of $\alpha-\mathrm{Fe}_{2} \mathrm{O}_{3}$ (ca. $15 \mathrm{~nm}$ ). Table 1 summarizes the morphological characteristics of these different regions.

The $\mathrm{Fe}_{3_{3}}$ and $\mathrm{L}_{2}$-edge $\mathrm{X}$-ray absorption spectra of the three regions at $250{ }^{\circ} \mathrm{C}$ are shown in Figure $2 \mathrm{~b}$. The change in relative abundance of $\mathrm{Fe}$ valence in these regions as a function of reduction temperature is shown in Figure 2c (and Figure S1 in the Supporting Information). By performing a least-squares linear combination fitting of the $\mathrm{Fe} \mathrm{L}_{3}$ and $\mathrm{L}_{2}$ edges at every $35 \times 35 \mathrm{~nm}^{2}$ pixel, a chemical component image of the catalyst particle was constructed at each reduction temperature (see the Supporting Information). $\mathrm{Fe}_{3} \mathrm{O}_{4}$, $\mathrm{Fe}_{2} \mathrm{SiO}_{4}$, and $\alpha-\mathrm{Fe}$ were used as references for mixed (1:2) $\mathrm{Fe}^{2+} / \mathrm{Fe}^{3+}\left(\mathrm{Fe}_{3} \mathrm{O}_{4}\right)$, pure $\mathrm{Fe}^{2+}$, and $\mathrm{Fe}^{0}$ species, respectively. $\mathrm{Fe}^{3+}$ has a characteristic main $\mathrm{L}_{3}$-edge contribution at $709.3 \mathrm{eV}, \mathrm{Fe}^{2+}$ at $707.9 \mathrm{eV}$, and $\mathrm{Fe}^{0}$ at $706.8 \mathrm{eV}$ (Figure 3, left). ${ }^{[10,16,18]}$ The maximum contribution of the each species was normalized to emphasize the spatial distribution. A valence contour map of the sample (Figure 3, right) was constructed by combining the relative contribution of each species and assigning valence numbers $\left(0\right.$ for $\mathrm{Fe}^{0}, 2$ for $\mathrm{Fe}^{2+}$ and $2^{2} / 3$ for $\mathrm{Fe}^{2+/ 3+}$ ) at every pixel.

$\mathrm{Up}$ to approximately $200^{\circ} \mathrm{C}$, the $\mathrm{Fe} \mathrm{L}_{3}$ - and $\mathrm{L}_{2}$-edge spectra indicated slow reduction of $\mathrm{Fe}^{3+}$ in $\alpha-\mathrm{Fe}_{2} \mathrm{O}_{3}$ to the mixed $\mathrm{Fe}^{2+}$ and $\mathrm{Fe}^{3+}$ (ratio 1:2) $\mathrm{Fe}_{3} \mathrm{O}_{4}$ phase. The bulk TPR data (Figure 1c) confirmed that below $200^{\circ} \mathrm{C}$ hardly any reduction takes place. At $250^{\circ} \mathrm{C}$, however, these data show that the material is reduced significantly and differences in reduction behavior were found between the defined regions. It is clear that region 1 largely remains in the mixed $\mathrm{Fe}^{2+} / \mathrm{Fe}^{3+}$ state (Figure $2 \mathrm{~b}$ and $3 \mathrm{a}$ ). The relatively low amount of $\mathrm{Fe}^{2+}$ indicates that the material is hardly reduced beyond $\mathrm{Fe}_{3} \mathrm{O}_{4}$ at this temperature. A significantly higher contribution from $\mathrm{Fe}^{2+}$ is observed in region 2. Apparently the $\mathrm{SiO}_{2}$ phase somehow stabilizes the $\mathrm{Fe}^{2+}$ species. This stabilization is usually ascribed to the formation of either $\mathrm{FeO}$ or a mixed oxide, such as $\mathrm{Fe}_{2} \mathrm{SiO}_{4} \cdot{ }^{[19,20]}$ In a more elaborate explanation, $\mathrm{SiO}_{2}$ may interact with the $\mathrm{Fe}^{2+} / \mathrm{Fe}^{3+} \mathrm{Fe}_{3} \mathrm{O}_{4}$ spinel phase in such a way that a mixed oxide $\mathrm{Fe}_{2} \mathrm{SiO}_{4}$ phase is formed. ${ }^{[20]} \mathrm{In}$ region 3 , the reduction to $\mathrm{Fe}^{0}$ has made significantly more progress than in the other regions. The thin layer of $\alpha-\mathrm{Fe}_{2} \mathrm{O}_{3}$ in 


\section{Communications}

a)

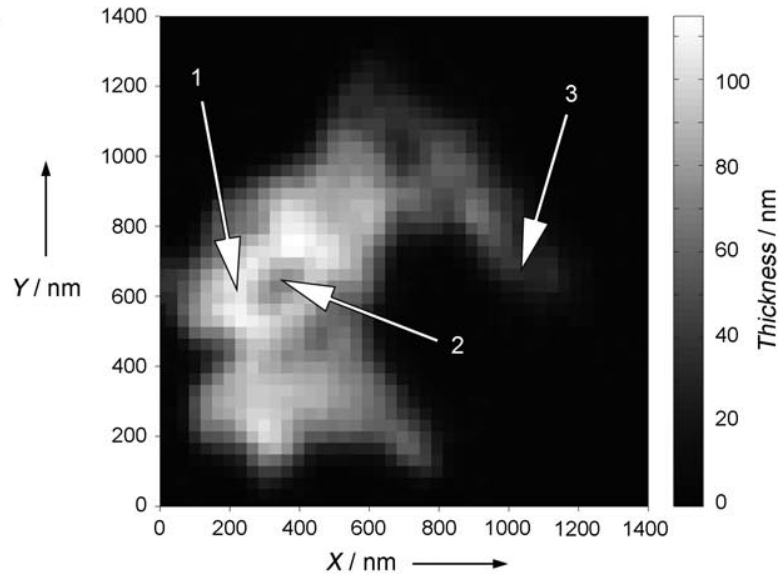

b)

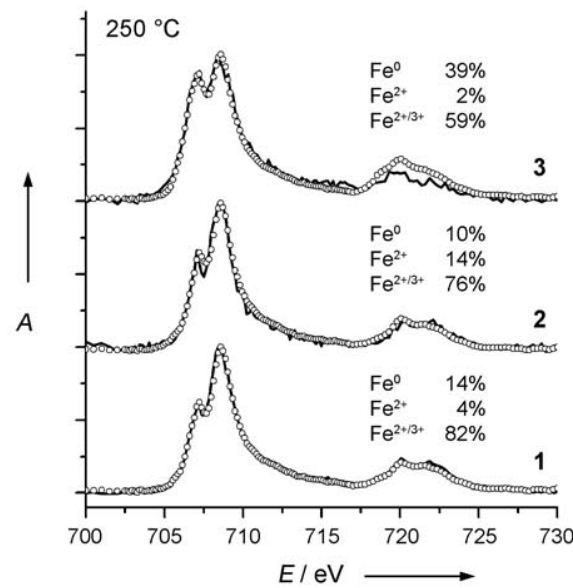

c)

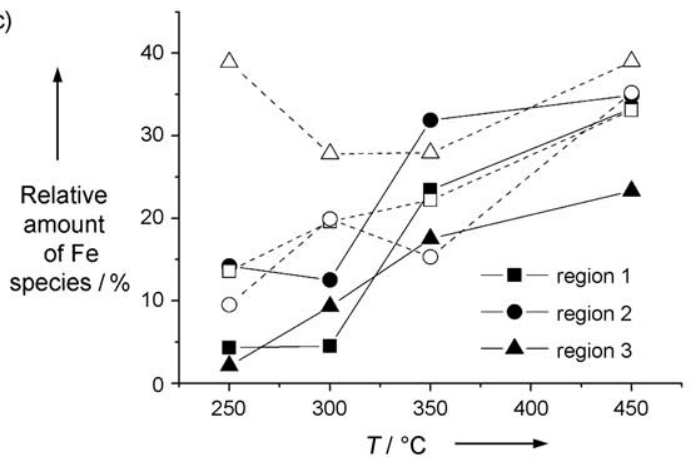

Figure 2. a) Thickness plot of the Fe-based FTS catalyst particle. Pixel dimensions are $35 \times 35 \mathrm{~nm}^{2}$. b) Fe $\mathrm{L}_{3}$ - and $\mathrm{L}_{2}$-edge spectra of the catalyst particle during the reduction treatment at $250^{\circ} \mathrm{C}$. Solid lines indicate experimental data from the defined regions in (a). Scattered symbols $(\circ)$ indicate fitted data. Relative contributions of the different Fe species, resulting from linear combination fitting, are indicated above each spectrum. c) The relative distribution of $\mathrm{Fe}^{0}$ and $\mathrm{Fe}^{2+}$ species as a function of temperature in the different regions. White symbols indicate $\mathrm{Fe}^{0}$, whereas black symbols indicate $\mathrm{Fe}^{2+}$. The remaining fraction is the amount of $\mathrm{Fe}^{2+/ 3+}$ species.

Table 1: Approximate layer thicknesses ( $t$ ) for the defined regions under discussion.

\begin{tabular}{clcc}
\hline Region & $t_{\mathrm{\alpha}-\mathrm{F} \mathrm{e}_{2} \mathrm{O}_{3}}[\mathrm{~nm}]$ & $t_{\mathrm{SiO}_{2}}[\mathrm{~nm}]$ & $t_{\text {total }}[\mathrm{nm}]$ \\
\hline 1 & 40 & 70 & 110 \\
2 & 20 & 50 & 70 \\
3 & 15 & 5 & 20 \\
\hline
\end{tabular}
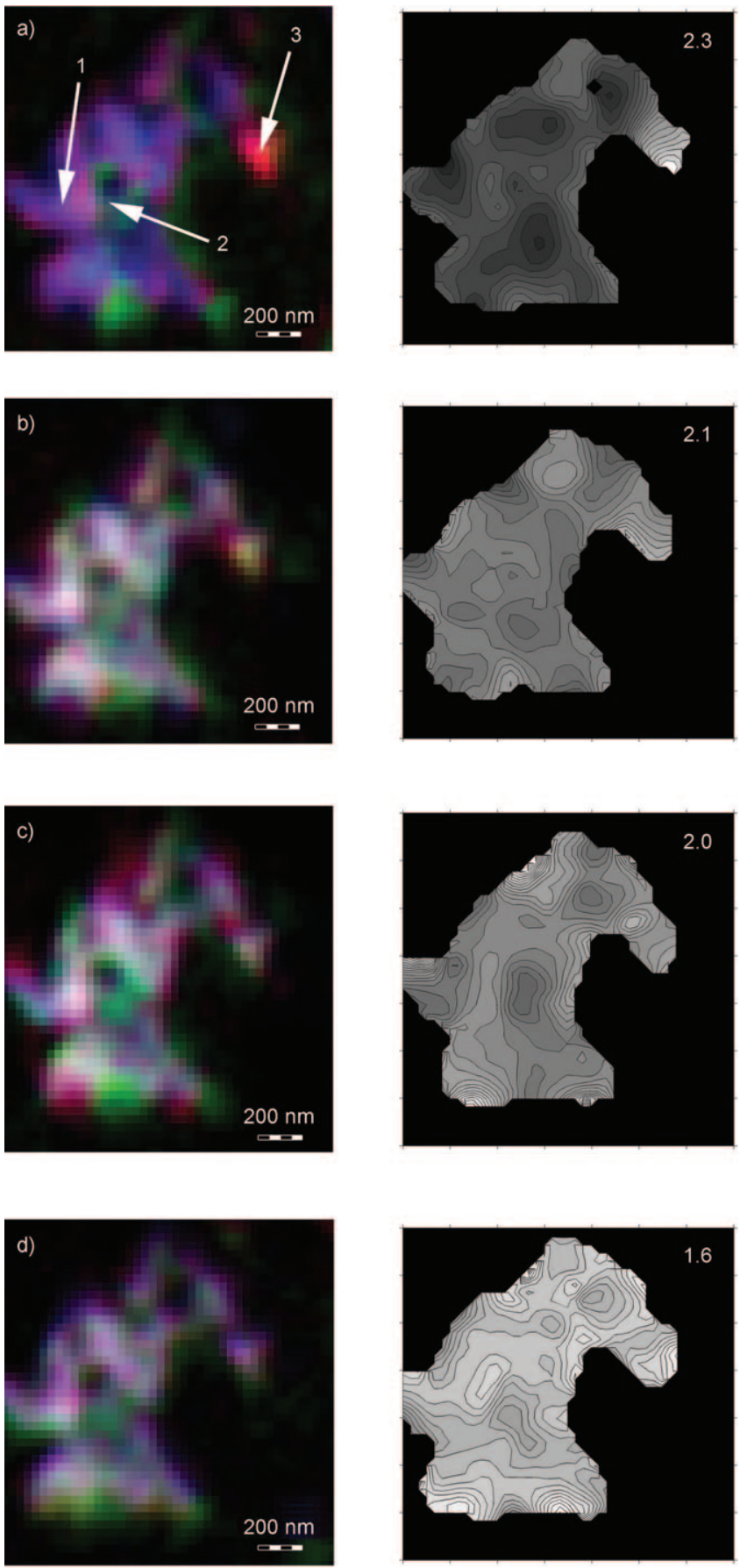

$\mathrm{Fe}^{0}$
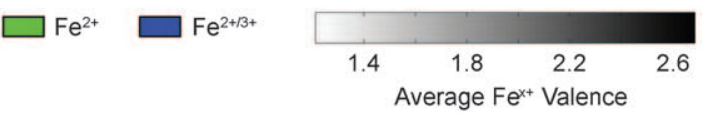

Figure 3. Chemical component images of the catalyst particle, showing the spatial distribution of the different iron species (left) and average valence contour maps (right) in 1 bar $\mathrm{H}_{2}$ at a) $250^{\circ} \mathrm{C}$, b) $300^{\circ} \mathrm{C}$, c) $350^{\circ} \mathrm{C}$ and d) $450^{\circ} \mathrm{C}$. The pixel dimensions (left column) are $35 \times 35 \mathrm{~nm}^{2}$. The three defined regions are indicated in (a). The average valence of the whole catalyst particle is indicated in the top right corner of the contour maps.

the absence of $\mathrm{SiO}_{2}$ in region 3 apparently leads to fast reduction of $\mathrm{Fe}^{3+}$ to $\mathrm{Fe}^{2+}$ and $\mathrm{Fe}^{0}$ species, even at $250^{\circ} \mathrm{C}$, as was also measured in additional STXM reduction experi- 
ments carried out on bulk $\alpha-\mathrm{Fe}_{2} \mathrm{O}_{3}$ (Figure $\mathrm{S} 2$ in the Supporting Information).

At $300^{\circ} \mathrm{C}$, the $\mathrm{Fe} \mathrm{L}$ edges of region 3 (Figure $2 \mathrm{c}$ ) show a somewhat lower contribution from $\mathrm{Fe}^{0}$ and more $\mathrm{Fe}^{2+}$ and mixed $\mathrm{Fe}^{2+} / \mathrm{Fe}^{3+}$ species compared to $250^{\circ} \mathrm{C}$. This change might be a direct indication of the migration of $\mathrm{Si}(\mathrm{OH})_{4}$ species over the catalyst. ${ }^{[19-21]}$ Owing to the enhanced mobility of $\mathrm{Si}$ species at higher temperatures, induced by reaction with $\mathrm{H}_{2} \mathrm{O}$ produced during reduction, $\mathrm{SiO}_{2}$ may spread over the catalyst, inhibiting the reduction of $\mathrm{Fe}$ species beyond $\mathrm{Fe}^{2+}$. In support of this hypothesis, the total thickness of region 3 appeared to increase between 250 and $300^{\circ} \mathrm{C}$. An accurate thickness calculation, however, remains difficult owing to the presence of multiple phases. Another explanation for the decrease in relative amount $\mathrm{Fe}^{0}$ species at $300^{\circ} \mathrm{C}$ might be a higher mobility for the metallic species. However, this effect is expected to be limited, especially in the case of supported catalysts. ${ }^{[22]}$ Regions 1 and 2 show an enhanced contribution of $\mathrm{Fe}^{2+}$ and $\mathrm{Fe}^{0}$ species and thus a lower average valence (Figure $2 \mathrm{c}$ and Figure $3 \mathrm{~b}$ ) compared to $250^{\circ} \mathrm{C}$, with the $\mathrm{SiO}_{2}$ rich region 2 showing a relatively higher abundance of $\mathrm{Fe}^{2+}$ species.

Increasing the temperature to $350^{\circ} \mathrm{C}$, leads to further reduction for regions 1 and 2 (Figure $2 \mathrm{c}$ ), with the distribution of Fe species becoming more homogeneous (Figure $3 \mathrm{c}$ ). However, some regions still show a higher concentration of $\mathrm{Fe}^{0}$ relative to $\mathrm{Fe}^{2+} /\left(\mathrm{Fe}^{2+} / \mathrm{Fe}^{3+}\right)$ species and a lower resulting average valence. At $450{ }^{\circ} \mathrm{C}$ (Figure $3 \mathrm{~d}$ ) all three regions show a $\mathrm{Fe}^{0} / \mathrm{Fe}^{2+} /\left(\mathrm{Fe}^{2+} / \mathrm{Fe}^{3+}\right)$ species ratio of about $1: 1: 1$. Increasing the temperature to $500^{\circ} \mathrm{C}$ showed a higher overall contribution of $\mathrm{Fe}^{2+}$ and $\mathrm{Fe}^{0}$ species (Figure S1 in the Supporting Information), but no significant differences in the spatial distribution of Fe species.

In summary, the reduction behavior of a single Fe-based FTS catalyst particle is dependent on its morphology up to $300^{\circ} \mathrm{C}$, after which the distribution of Fe over the particle becomes more and more homogeneous with increasing temperature. $\mathrm{Fe}^{2+}$ in close contact with $\mathrm{SiO}_{2}$ is stabilized from further reduction to $\mathrm{Fe}^{0}$. The mobility of $\mathrm{SiO}_{2}$ might increase by reaction with $\mathrm{H}_{2} \mathrm{O}$ at higher temperatures. As a result, above $300^{\circ} \mathrm{C}$, no regions are observed where $\mathrm{Fe}^{0}$ is the main contributing species. Furthermore, Fe species could not be fully reduced to $\mathrm{Fe}^{0}$ at temperatures below $500^{\circ} \mathrm{C}$. The lowest detected average valence was 1.4 at $500^{\circ} \mathrm{C}$, indicating a substantial contribution from $\mathrm{Fe}^{2+}$ and $\mathrm{Fe}^{3+}$ species. In a more general perspective, we have shown that the use of in situ STXM provides new insights into the local morphologically and chemically dependent reduction behavior of a catalytic solid. It also illustrates the complexity of the interpretation of bulk reduction experiments and their extrapolation to nanoscale phenomena.

\section{Experimental Section}

In situ STXM: The experimental setup ${ }^{[10]}$ and nanoreactor ${ }^{[7]}$ are described in detail elsewhere. All experiments were performed on the STXM microscope at beamline 10ID-1 (SM) at the Canadian Light Source in Saskatoon, Canada. ${ }^{[23]}$ Monochromatic X-ray light was focused using a Fresnel-type zone plate lens (outermost zone width $35 \mathrm{~nm}$ ) resulting in a spatial resolution of about $40 \mathrm{~nm}$. The reactor was mounted on a piezoelectric sample stage, used to focus and produce $(x, y)$ raster scans of the sample. Transmitted light was detected by a scintillator combined with a photomultiplier tube. The nanoreactor consisted of a reactor chamber (ca. $500 \times 500 \times 50 \mu \mathrm{m})$ connected to $\mu \mathrm{m}$-sized gas channels and equipped with a Pt heater. ${ }^{[7]}$ Owing to the small dimensions involved, the $50^{\circ} \mathrm{C}$ temperature increments were almost instantaneously achieved. After each increment, the temperature was kept constant for 30 min before acquiring STXM image data.

Temperature programmed reduction (TPR) was performed using a Micromeritics Autochem-II instrument equipped with a TCD detector. Before the experiments, the sample was dried in an Ar flow at $120^{\circ} \mathrm{C}$ for $20 \mathrm{~min}$. After the TCD signal was stable, the gas stream was switched to $5 \% \mathrm{H}_{2} / \mathrm{Ar}\left(50 \mathrm{~mL} \mathrm{~min}^{-1}\right)$. The temperature was raised with increments of $50^{\circ} \mathrm{C}$ up to $500^{\circ} \mathrm{C}$ at $20^{\circ} \mathrm{Cmin}^{-1}$. After each increment, the temperature was kept constant for $30 \mathrm{~min}$.

Catalyst: The $\mathrm{Fe}_{2} \mathrm{O}_{3} / \mathrm{CuO} / \mathrm{K}_{2} \mathrm{O} / \mathrm{SiO}_{2}$ catalyst was synthesized using a reported procedure. ${ }^{[10]}$ The catalyst material was ground, suspended in ethanol, treated in an ultrasonic bath, and loaded by flowing the suspension through the nanoreactor and subsequent drying.

Received: December 9, 2008

Published online: February 10, 2009

Keywords: heterogeneous catalysis - iron . scanning probe microscopy - supported catalysts . X-ray absorption spectroscopy

[1] a) M. B. J. Roeffaers, B. F. Sels, H. Uji-i, F. C. De Schryver, P. A. Jacobs, D. E. De Vos, J. Hofkens, Nature 2006, 439, 572; b) M. B. J. Roeffaers, B. F. Sels, H. Uji-i, B. Blanpain, P. L'Hoest, P. A. Jacobs, F. C. De Schryver, J. Hofkens, D. E. De Vos, Angew. Chem. 2007, 119, 1736; Angew. Chem. Int. Ed. 2007, 46, 1706; c) M. B. J. Roeffaers, G. De Cremer, H. Uji-i, B. Muls, B. F. Sels, P. A. Jacobs, F. C. De Schryver, D. E. De Vos, J. Hofkens, Proc. Natl. Acad. Sci. USA 2007, 104, 12603.

[2] a) M. H. F. Kox, E. Stavitski, B. M. Weckhuysen, Angew. Chem. 2007, 119, 3726; Angew. Chem. Int. Ed. 2007, 46, 3652; b) E. Stavitski, M. H. F. Kox, B. M. Weckhuysen, Chem. Eur. J. 2007, 13, 7057; c) E. Stavitski, M. H. F. Kox, I. Swart, F. M. F. de Groot, B. M. Weckhuysen, Angew. Chem. 2008, 120, 3599; Angew. Chem. Int. Ed. 2008, 47, 3543.

[3] a) A. Zürner, J. Kirstein, M. Doblinger, C. Brauchle, T. Bein, Nature 2007, 450, 705; b) W. Xu, J. S. Kong, Y.-T. E. Yeh, P. Chen, Nat. Mater. 2008, 7, 992; c) A. Urakawa, N. Maeda, A. Baiker, Angew. Chem. 2008, 120, 9396; Angew. Chem. Int. Ed. 2008, 47, 9256.

[4] a) H. H. Rotermund, W. Engel, M. Kordesch, G. Ertl, Nature 1990, 343, 355; b) T. Zambelli, J. Wintterlin, J. Trost, G. Ertl, Science 1996, 273, 1688; c) H. Over, Y. D. Kim, A. P. Seitsonen, S. Wendt, E. Lundgren, M. Schmid, P. Varga, A. Morgante, G. Ertl, Science 2000, 287, 1474; d) S. H. Kim, J. Mendez, J. Wintterlin, G. Ertl, Phys. Rev. B 2005, 72, 155414.

[5] a) B. L. M. Hendriksen, S. C. Bobaru, J. W. M. Frenken, Top. Catal. 2005, 36, 43; b) J. W. M. Frenken, B. L. M. Hendriksen, MRS Bull. 2007, 32, 1015.

[6] a) T. W. Hansen, J. B. Wagner, P. L. Hansen, S. Dahl, H. Topsoe, C. J. H. Jacobsen, Science 2001, 294, 1508; b) P. L. Hansen, J. B. Wagner, S. Helveg, J. R. Rostrup-Nielsen, B. S. Clausen, H. Topsoe, Science 2002, 295, 2053; c) P. L. Gai, E. D. Boyes, S. Helveg, P. L. Hansen, S. Giorgio, C. R. Henry, MRS Bull. 2007, 32,1044 . 


\section{Communications}

[7] J. F. Creemer, S. Helveg, G. H. Hoveling, S. Ullmann, A. M. Molenbroek, P. M. Sarro, H. W. Zandbergen, Ultramicroscopy 2008, 108, 993.

[8] a) H. Ade in Experimental Methods in the Physical Sciences, Vol. 32 (Eds.: R. Cellota, T. Lucatorto), Academic Press, New York, 1998, p. 225; b) T. Warwick, K. Franck, J. B. Kortright, G. Meigs, M. Moronne, S. Myneni, E. Rotenberg, S. Seal, W. F. Steele, H. Ade, A. Garcia, S. Cerasari, J. Delinger, S. Hayakawa A. P. Hitchcock, T. Tyliszczak, J. Kikuma, E. G. Rightor, H. J. Shin, B. P. Tonner, Rev. Sci. Instrum. 1998, 69, 2964.

[9] I. J. Drake, T. C. N. Liu, M. Gilles, T. Tyliszczak, A. L. D. Kilcoyne, D. K. Shuh, R. A. Mathies, A. T. Bell, Rev. Sci. Instrum. 2004, 75, 3242.

[10] a) E. de Smit, I. Swart, J. F. Creemer, G. H. Hoveling, M. K. Gilles, T. Tyliszczak, P. J. Kooyman, H. W. Zandbergen, C. Morin, B. M. Weckhuysen, F. M. F. de Groot, Nature 2008, 456, 222; b) A. T. Bell, Nature 2008, 456, 185.

[11] M. E. Dry in Catalysis: Science and Technology, Vol. 1 (Eds.: J. R. Anderson, M. Boudart), Springer, New York, 1981, p. 160

[12] E. de Smit, B. M. Weckhuysen, Chem. Soc. Rev. 2008, 37, 2758.

[13] D. B. Bukur, L. Nowicki, R. K. Manne, X. S. Lang, J. Catal. 1995, $155,366$.
[14] C. H. Bartholomew, M. W. Stoker, L. Mansker, A. Datye, Stud. Surf. Sci. Catal. 1999, 126, 265.

[15] F. M. F. de Groot, M. Grioni, J. C. Fuggle, J. Ghijsen, G. A. Sawatzky, H. Petersen, Phys. Rev. B 1989, 40, 5715.

[16] W. M. Heijboer, A. A. Battiston, A. Knop-Gericke, M. Havecker, R. Mayer, H. Bluhm, R. Schlögl, B. M. Weckhuysen, D. C. Koningsberger, F. M. F. de Groot, J. Phys. Chem. B 2003, 107, 13069.

[17] T. Sharp, Z. Wu, F. Seifert, B. Poe, M. Doerr, E. Paris, Phys. Chem. Miner. 1996, 23, 17.

[18] F. M. F. de Groot, A. Kotani, Core Level Spectroscopy of Solids, Taylor \& Francis, New York, 2008

[19] A. F. H. Wielers, A. J. H. M. Kock, C. E. C. A. Hop, J. W. Geus, A. M. van Der Kraan, J. Catal. 1989, 117, 1.

[20] C. R. F. Lund, J. A. Dumesic, J. Catal. 1981, 72, 21.

[21] D. H. Everett, J. M. Haynes, P. J. McElroy, Nature 1970, 226, 1033.

[22] Y. Jin, A. K. Datye, J. Catal. 2000, 196, 8.

[23] K. V. Kaznatcheev, C. Karunakaran, U. D. Lanke, S. G. Urquhart, M. Obst, A. P. Hitchcock, Nucl. Instrum. Methods Phys. Res. Sect. A 2007, 582, 96. 